\title{
Radiation-induced Mucositis in Patients with Oropharyngeal Cancer Treated with Moderate Acceleration of Intensity-modulated Radiation Therapy and Simultaneous Integrated Boost Concomitant with Weekly Cisplatin
}

\author{
Lenche Kostadinova $^{1 *}$, Gjusen Selim ${ }^{2}$, Petar Chakalaroski ${ }^{1}$, Snezana Smickoska ${ }^{1}$, Marina V. Stoleska ${ }^{1}$, Danilo Nonkuloski ${ }^{3}$ \\ ${ }^{1}$ University Clinic of Radiotherapy and Oncology, Skopje, Republic of Macedonia; ${ }^{2}$ University Clinic of Nephrology, Skopje, \\ Republic of Macedonia; ${ }^{3}$ University Clinic for Pediatric Diseases, Skopje, Republic of Macedonia
}

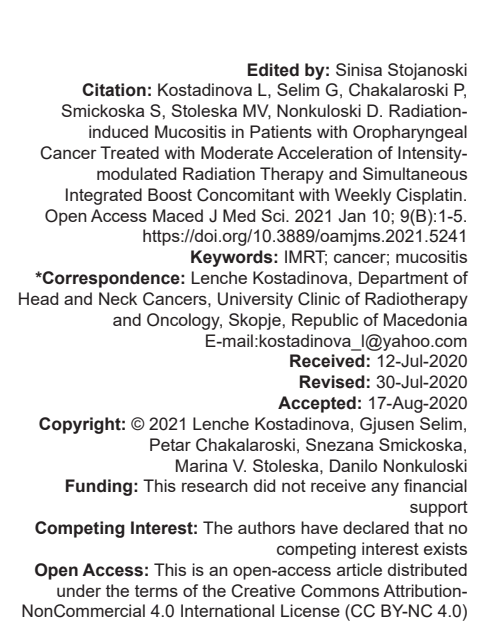

Introduction

Oropharyngeal squamous cell carcinoma belongs to group of rare solid head-and-neck tumors with global annual incidence of $0.9 / 100,000$. In year 2018, there were registered 92,887 new cases and 51,005 death from this disease [1]. The most common presentation is tonsil, followed by base of tongue, soft palate, and posterior pharyngeal wall. Definitive radiotherapy combined with concomitant chemotherapy is the treatment of choice for locally advanced oropharyngeal carcinoma with significant better overall survival and time to progression compared to other treatment modalities [2], [3].

Definitive radiotherapy, as a treatment of choice for planocellular oropharyngeal carcinoma, causes acute and late radiation-induced adverse events. Concomitant chemotherapy with radiotherapy other than increasing locoregional disease control and survival, it also increases acute toxicity during therapy [4,] [5], [6]. Radiation-induced mucositis represents one of the limiting factors during realization of radiotherapy causing pain, difficulty swallowing and chewing, and decreasing the quality of life. Mucositis is reaction of mucosa caused by radiation followed by inflammation, ulceration, and healing. When confluent mucositis reaches the maximum, further increasing of dose and cell death will not cause increasing of grade of mucositis. It will only affect duration of mucositis and recovering process [7]. Intensity and duration of acute mucositis depend on tumor localization, tumor size, daily dose in fraction, duration of radiotherapy, and technique of radiotherapy. It also depends on mucosal surface covered by radiation and patient's general condition.

Intensity-modulated radiation therapy (IMRT) with simultaneous integrated boost (SIB) represents an 
advanced form of radiotherapy technique in the treatment of oropharyngeal carcinoma, enabling precision cancer targeting with reducing dose to healthy normal tissues [8]. Simultaneous delivery of different doses in different regions in the same fraction with IMRT-SIB allows higher homogeneity, conformity, and consistency of dose in tumor volume [9], [10]. Advantage of this technique is delivering lower dose to critical structures and capability of treatment acceleration which will result in reducing of treatment time and escalation of dose in tumor volume [11]. IMRT-SIB achieves delivering higher dose in tumor and causes mucositis but lowers dose in fraction to other mucosal regions enabling minimization of mucosal radiation toxicity. Lower dose in fraction in elective regions reduces radiodermatitis in irradiated region. Otherwise, with increasing conformity in high- dose regions, we can reduce long-term dysphagia and tracheal toxicity. All of this indicate that beside certain regions which are irradiated with high dose, simultaneous irradiated regions with lower dose in IMRT-SIB technique will reduce acute and late radiation-induced toxicities [10], [12].

\section{Aim}

The aim of this study is to present maximum grade and duration of a maximum grade of radiationinduced acute mucositis, influence of total volume of oral mucosa, and volumes of oral mucosa which are encompassed with radiation volume of $54 \mathrm{~Gy}$ and 66 Gy on expression of grade of acute mucositis and influence of primary origin of tumor on encompassing with radiation volumes in patients treated with moderate acceleration with IMRT-SIB and concomitant weekly cycle of chemotherapy with cisplatin.

\section{Materials and Methods}

\section{Patients characteristics}

This planned non-randomized research represents study on 30 patients with advanced oropharyngeal carcinoma treated at University Clinic of Radiotherapy and Oncology - Skopje, Republic of Macedonia, from September 2017 to September 2019 with moderate acceleration with IMRT-SIB and concomitant weekly cycle of chemotherapy with cisplatin. Detailed patients characteristics are shown in Table 1 with stratification by gender, age, localization of primary tumor, and stage. Patients are staged according to eighth edition American Joint Committee on Cancer [13].

\section{Treatment}

Patient immobilization for computed tomography (CT) simulation is in supine position with
Table 1: Patients characteristics $(n=30)$

\begin{tabular}{ll}
\hline Characteristics & Number of patients (\%) \\
\hline Gander & $26(87)$ \\
Male & $4(13)$ \\
Female & \\
Age, years & 59.4 \\
Middle & $30-70$ \\
Range & \\
Localization of primary tumor & $17(65)$ \\
Tonsils & $8(15)$ \\
Base of tongue & $3(12)$ \\
Posterior wall of hypopharynx & $2(8)$ \\
Soft palate & \\
T (Primary tumor) & $7(23)$ \\
T3 & $6(54)$ \\
T4a1 & $7(23)$ \\
T4b & \\
N (regional lymph nodes) & $3(10)$ \\
N0 & $6(20)$ \\
N1 & $7(23)$ \\
N2b & $5(17)$ \\
N2c & $9(30)$ \\
N3b & \\
Stage & $4(13)$ \\
III & $14(47)$ \\
IVA & $12(40)$ \\
IVB &
\end{tabular}

hyperextended neck. We use thermoplastic mask for immobilization of head, neck, and shoulder to reproduce always the same position during treatment. CT simulation for treatment planning is performed on $2.5 \mathrm{~mm}$ transverse cross-sections without intravenous contrast. Delineation of targeted volumes was according to protocol study Radiation Therapy Oncology Group (RTOG) H-0022 [14].

Gross tumor volume-P66 (GTV-P66) is the primary tumor and gross tumor volume-N66 (GTV-N66) represents the metastatic lymph nodes determined with endoscopy, CT, and magnetic resonance imaging. GTV 66 is obtained with integration of these two volumes which included primary disease. Analogous to the previous volumes is added CTV-P66 and CTV-N66 (clinical target volume - CTV66) which are obtained by expanding GTV for $0.5 \mathrm{~mm}$. After this, we delineated elective regions with lymph nodes in the neck (CTV-N54) where there are included metastatic lymph nodes (GTV-N66) with margin expansion from $1 \mathrm{~cm}$ to $2 \mathrm{~cm}$ and CTV-P54 with margin expansion from 1 to $2 \mathrm{~cm}$ from GTV-P66. With integration of CTV-N54 and CTV-P54, clinical target volume (CTV54) is created. Planning target volume - PTV66 and PTV54 are represented with geometrical margin of $5 \mathrm{~mm}$ around CTV-N54 and CTV-P54 (Figure 1).

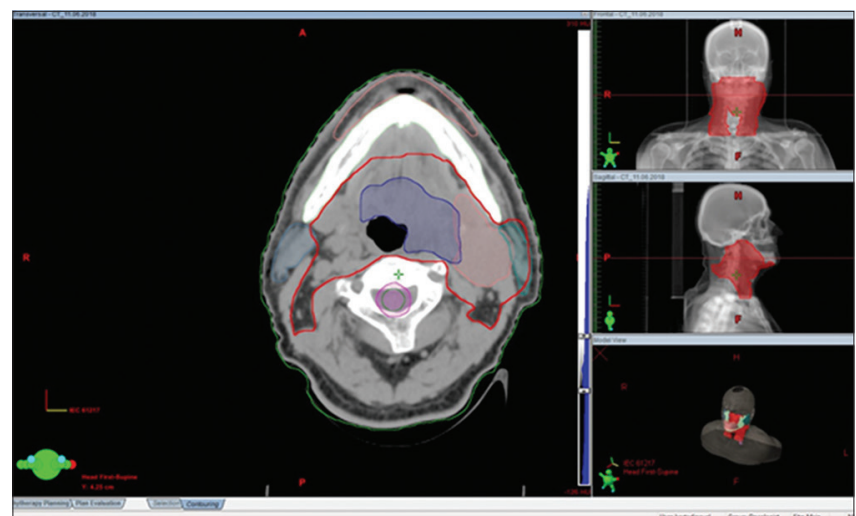

Figure 1: Delineated and integrated CTN-N54 and CTV-P54 
As normal structure of interest that was delineated in every patient was oral mucosa. Main interests of this research were volume of oral mucosa encompassed with 54 Gy which is cross-section between the total oral mucosa and PTV54 and oral mucosa encompassed with 66 Gy which is cross-section between the total oral mucosa and PTV66 consequently obtaining a volume of the total oral mucosa which is irradiated with 54 Gy or 66 Gy (Figure 2).

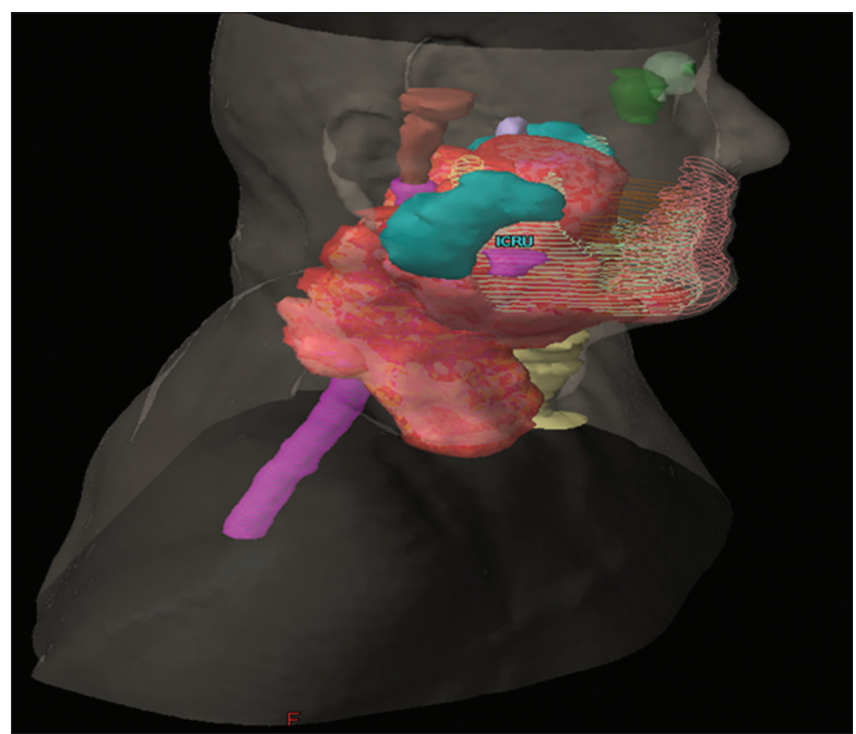

Figure 2: Three-dimensional view after delineated and integrated planning target volumes and organs at risk

IMRT-SIB technique used in this study is based on the RTOG H-0022 study [14]. Patients were irradiated once daily, 5 days in the week with total tumor dose till 66 Gy in 30 fractions. GTV as high-risk area was irradiated with dose $2.2 \mathrm{~Gy}$ in fraction and in the same time in same fraction $1.8 \mathrm{~Gy}$ was given to elective irradiated area CTV54 (Figure 3) [15].

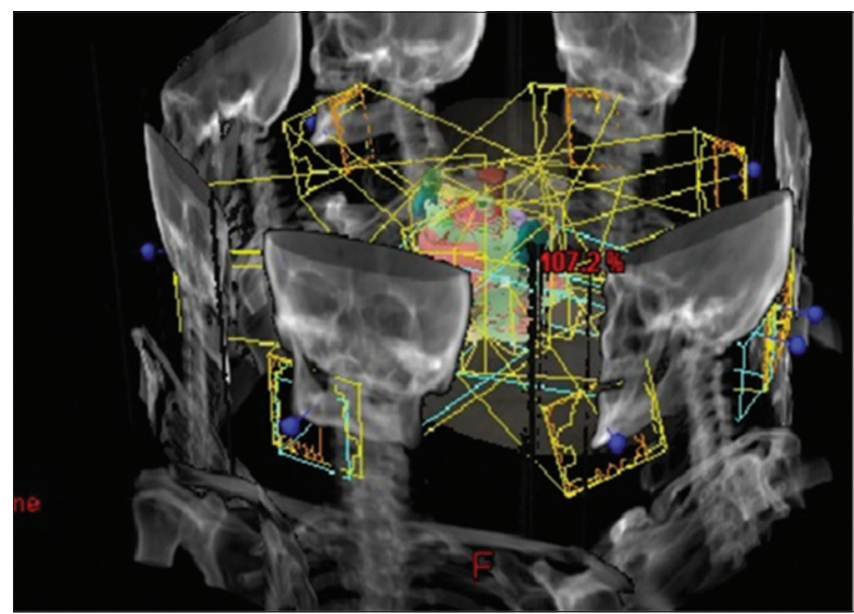

Figure 3: Planning and scheduling the fields using IMRT technique

Planning and scheduling the fields with this technique allows more sparing of healthy tissue and consecutively high quality of life in patients with oropharyngeal cancer [10], [11].

All of the patients, starting from the $1^{\text {st }}$ week then once weekly, received concurrent chemotherapy, during radiotherapy, cisplatin $30 \mathrm{mg} / \mathrm{m}^{2}$, total of 6 times during the entire treatment. The day when cisplatin is administered, radiotherapy fraction is realized in 1-3 $\mathrm{h}$ after chemotherapy. A total number of 6 cycles of weekly concurrent cisplatin were administrated in 15 patients (50\%), 5 cycles in 8 patients $(27 \%)$, and in the remaining number of patients $(23 \%),<5$ cycles were administered. Mean total dose of administered concurrent cisplatin in all patients was $247 \mathrm{mg} / \mathrm{m}^{2}$.

\section{Assessment of acute mucositis}

All patients were monitored once weekly in the period of 6 weeks during the radiation therapy in combination with concomitant chemotherapy. An assessment of radiation-induced acute mucositis was performed according to acute radiation morbidity scoring criteria of the RTOG with quantum descriptive scoring system from 0 to 4 (Table 2) [16].

Table 2: Grade of acute mucosal reaction according to quantum descriptive scoring system from 0 to 4 of RTOG

\begin{tabular}{lllll}
\hline 0 & 1 & 2 & 3 & 4 \\
\hline $\begin{array}{l}\text { Without } \\
\text { changes }\end{array}$ & $\begin{array}{l}\text { weak pain } \\
\text { weal }\end{array}$ & $\begin{array}{l}\text { Punctiform mucositis/ld } / \text { middle pain } \\
\text { Confluent mucositis/ } /\end{array}$ & $\begin{array}{l}\text { Necrosis, ulceration, } \\
\text { strong pain }\end{array}$ & hemorrhagia \\
\hline RTOG: Radiation Therapy Oncology Group. & &
\end{tabular}

RTOG: Radiation Therapy Oncology Group.

\section{Results}

Characteristics of radiation-induced mucositis monitored during 6 weeks are presented in Table 3 . Maximum grade of acute mucositis reaction was Grade 3 and was manifested in 27 patients (90\%). Maximum time of duration of confluent mucositis was 28 days (range 7-28) and median duration of Grade 3 mucositis was 18 days (range $7-28$ ).

Table 3: Characteristics of acute mucosal reactions on total oral

\begin{tabular}{ll}
\hline Characteristics & Number of patients (\%) \\
\hline Maximum grade of acute reaction & $3(10)$ \\
$\quad$ Grade 2 & $27(90)$ \\
$\quad$ Grade 3 & \\
Time to occurrence Grade 2 reaction/days & 22.6 \\
$\quad$ Average & $7-35$ \\
$\quad$ Range & 12.3 \\
Duration of Grade 2 mucositis/days & $7-35$ \\
$\quad$ Average & \\
$\quad$ Range & 27.5 \\
Time to occurrence Grade 3 reaction/days & $21-35$ \\
$\quad$ Average & \\
$\quad$ Range & 14.2 \\
Duration of Grade 3 mucositis/days & $7-28$ \\
$\quad$ Average & \\
Range &
\end{tabular}

The statistical methods used in this research were t-test and ANOVA.

Table 4 contains statistically obtained results information from comparing between volume of total oral mucosa, volume of oral mucosa encompassed with dose of $54 \mathrm{~Gy}$, and volume of oral mucosa encompassed with 66 Gy with expression of acute mucositis Grade 2 and 3 in the $5^{\text {th }}$ week of radiotherapy. 
Table 4: Comparison between volume of oral mucosa with Grade 2 versus Grade 3 radiation-induced mucositis in the $5^{\text {th }}$ week of radiotherapy

\begin{tabular}{|c|c|c|c|}
\hline \multirow[t]{3}{*}{ Volume of oral mucosa $\left(\mathrm{cm}^{3}\right) \pm \mathrm{SD}$} & \multicolumn{2}{|c|}{$\begin{array}{l}\text { Degree of radiation-induced } \\
\text { mucositis }\end{array}$} & \multirow[t]{3}{*}{$\mathrm{p}$ value } \\
\hline & Grade 2 & Grade 3 & \\
\hline & $\begin{array}{l}\text { Number of } \\
\text { patients }=5\end{array}$ & $\begin{array}{l}\text { Number of } \\
\text { patients }=25\end{array}$ & \\
\hline Total volume of oral mucosa & $138.6 \pm 29.48$ & $122.88 \pm 22.01$ & 0.168 \\
\hline $\begin{array}{l}\text { Volume of oral mucosa encompass } \\
\text { with dose of } 54 \mathrm{~Gy}\end{array}$ & $77.80 \pm 28.95$ & $83.30 \pm 29.61$ & 0.706 \\
\hline $\begin{array}{l}\text { Volume of oral mucosa encompass } \\
\text { with dose of } 66 \mathrm{~Gy}\end{array}$ & $51.40 \pm 29.13$ & $62.78 \pm 29.10$ & 0.431 \\
\hline
\end{tabular}

with dose of 66 Gy

Results from comparison between investigated volumes of oral mucosa and expression of grade of acute mucositis in the $5^{\text {th }}$ week were statistically nonsignificant $(p>0.05)$.

Table 5 contains statistically obtained results information from comparing volume of total oral mucosa, volume of oral mucosa encompassed with dose of $54 \mathrm{~Gy}$, and volume of oral mucosa encompassed with dose of 66 Gy with Grade 2 mucositis (punctiform mucositis) and Grade 3 mucositis (confluent mucositis) in the $6^{\text {th }}$ week of radiotherapy. There was statistically non-significant difference $(p>0.05)$ between volumes of oral mucosa and expression of degree of radiation-induced mucositis.

Table 5: Comparison between volume of oral mucosa with Grade 2 versus Grade 3 radiation-induced mucositis in the $6^{\text {th }}$ week of radiotherapy

\begin{tabular}{|c|c|c|c|}
\hline \multirow[t]{3}{*}{ Volume of oral mucosa $\left(\mathrm{cm}^{3}\right) \pm \mathrm{SD}$} & \multicolumn{2}{|c|}{$\begin{array}{l}\text { Degree of radiation-induced } \\
\text { mucositis }\end{array}$} & \multirow[t]{3}{*}{$p$ value } \\
\hline & Grade 2 & Grade 3 & \\
\hline & $\begin{array}{l}\text { Number of } \\
\text { patients }=11\end{array}$ & $\begin{array}{l}\text { Number of } \\
\text { patients }=19\end{array}$ & \\
\hline Total volume of oral mucosa & $131.69 \pm 27.30$ & $122.00 \pm 21.17$ & 0.286 \\
\hline $\begin{array}{l}\text { Volume of oral mucosa encompass } \\
\text { with dose of } 54 \text { Gy }\end{array}$ & $76.47 \pm 33.61$ & $85.81 \pm 26.48$ & 0.406 \\
\hline $\begin{array}{l}\text { Volume of oral mucosa encompass } \\
\text { with dose of } 66 \mathrm{~Gy}\end{array}$ & $50.23 \pm 29.97$ & $67.05 \pm 27.18$ & 0.126 \\
\hline
\end{tabular}

Table 6 shows statistically obtained results information from comparing volume of total oral mucosa, volumes of oral mucosa encompassed with dose of 54 Gy and 66 Gy with localization of primary origin of cancer or oropharyngeal cancer originating from the base of the tongue versus the cancers originating from the tonsillar region, soft palate, and pharyngeal wall. In patients, whose oropharyngeal cancer originates from base of tongue, a statistically significant difference was

Table 6: Comparison between volume of oral mucosa in patient with oropharyngeal cancer originates from base of tongue versus cancers originating from tonsils, soft palate, and pharyngeal wall

\begin{tabular}{|c|c|c|c|}
\hline \multirow{2}{*}{$\begin{array}{l}\text { Volume of oral mucosa } \\
\left(\mathrm{cm}^{3}\right) \pm \mathrm{SD}\end{array}$} & \multicolumn{2}{|c|}{ Localization of primary oropharyngeal origin } & \multirow[t]{2}{*}{$p$ value } \\
\hline & $\begin{array}{l}\text { Carcinoma originates } \\
\text { from base of tongue } \\
\text { Number of patients }=8\end{array}$ & $\begin{array}{l}\text { Carcinoma originating } \\
\text { from tonsils, soft palate, } \\
\text { and pharyngeal wall } \\
\text { Number of patients }=22\end{array}$ & \\
\hline $\begin{array}{l}\text { Total volume of oral } \\
\text { mucosa }\end{array}$ & $119.49 \pm 12.31$ & $127.76 \pm 26.47$ & 0.405 \\
\hline $\begin{array}{l}\text { Volume of oral mucosa } \\
\text { encompass with dose } \\
\text { of } 54 \mathrm{~Gy}\end{array}$ & $90.37 \pm 19.58$ & $79.48 \pm 31.73$ & 0.373 \\
\hline $\begin{array}{l}\text { Volume of oral mucosa } \\
\text { encompass with dose } \\
\text { of } 66 \mathrm{~Gy}\end{array}$ & $78.63 \pm 25.35$ & $54.43 \pm 27.87$ & 0.040 \\
\hline
\end{tabular}

obtained $(p=0.040)$ on the volume of the oral mucosa covered by PTV66 in relation to other localizations (cancers originating from tonsils, soft palate, and pharyngeal wall).

\section{Discussion}

The main goal in radiotherapy is better targeting on tumor cells with minimal damage on surrounding healthy tissues which are a limiting factor in determining the prescribed dose of radiotherapy. Radiation-induced mucositis is one of the limiting factors during radiotherapy, disturbing the quality of life and in some cases leading to discontinuation of therapy. Which grade of acute mucositis will appear during radiotherapy depends on multiple factors such as dose in fraction, added concomitant chemotherapy, size of the tumor, and technique of radiotherapy. They also include the factors investigated in this research: Tumor localization and volume encompassed with planning targeted volume. Incidence of acute confluent mucositis with strong pain was present in $90 \%$ of the patients. Comparison between volumes of oral mucosa with expression of grade of acute mucositis in the past 2 weeks in radiotherapy showed statistically nonsignificant difference. Results from this research showed that encompassed volume of total mucosa with planning target volume of $66 \mathrm{~Gy}$ is bigger when localization of the primary tumor is base of the tongue compared to other localization of oropharyngeal cancers.

\section{Conclusion}

According to the summarizing results obtained from this research, we can recommend delineating of oral mucosa during planning radiotherapy as a standard routine procedure and application of new modern radiotherapy techniques with better conformity and homogeneity of the dose, like IMRT-SIB to reduce side effects which significantly affect the quality of life during treatment.

\section{References}

1. WHO/NMH/CHP/HPR/ORH. Global Data on Incidence of Ora Cancer, Oral Health Programme, World Health Organization. https://doi.org/10.4314/ajoh.v1i1.31299

2. Krstevska V, Stojkovski I, Zafirova-Ivanovska B. Concurrent radiochemotherapy in locally-regionally advanced oropharyngeal squamous cell carcinoma: Analysis of treatment results and prognostic factors. Radiat Oncol. 2012;7(1):78. 
https://doi.org/10.1186/1748-717x-7-78

\section{PMid:22640662}

3. Pignon J, Bourhis J, Domenge C, Designé L. Chemotherapy added to locoregional treatment for head and neck squamouscell carcinoma: Three meta-analyses of updated individual data. $\mathrm{MACH}-\mathrm{NC}$ collaborative group. Meta-analysis of chemotherapy on head and neck cancer. Lancet. 2000;355(9208):949-55. https://doi.org/10.1016/s0140-6736(00)90011-4 PMid:10768432

4. Trotti A. Toxicity in head and neck cancer: A review of trends and issues. Int J Radiat Oncol Biol Phys. 2000;47(1):1-12.

PMid:10758302

5. Narayan S, Lehmann J, Coleman M, Vaughan A, Yang C, Enepekides D, et al. Prospective evaluation to establish a dose response for clinical oral mucositis in patients undergoing headand-neck conformal radiotherapy. Int J Radiat Oncol Biol Phys. 2008;72(3):756-62. https://doi.org/10.1016/j.jrobp.2008.01.060 PMid:18417299

6. Adelstein D, Li Y, Adams G, Wagner H, Kish J, Ensley J, et al. An intergroup Phase III comparison of standard radiation therapy and two schedules of concurrent chemoradiotherapy in patients with unresectable squamous cell head and neck cancer. J Clin Oncol. 2003;21(1):92-8. https://doi.org/10.1200/ jco.2003.01.008

PMid:12506176

7. Krstevska V, Lukarski D, Zafirova-Ivanovska B, Stojkovski I. Acute Mucosal Reactions in Patients with Advanced Head and Neck Cancer Treated with Concurrent Chemoradiotherapy. (Conference). Skopje: Association for Medical Physics and Biomedical Engineering; 2019. Available from: https://www.osti. gov/etdeweb/biblio/21547142. [Last accessed on 2019 Nov 02].

8. National Comprehensive Cancer Network (NCCN), Clinical Practice Guidelines in Oncology, Head-and-Neck. https://doi.org/10.1002/hed.24866

9. McQuaid D, Dunlop A, Nill S, Franzese C, Nutting C, Harrington $\mathrm{K}$, et al. Evaluation of radiotherapy techniques for radical treatment of lateralised oropharyngeal cancers:
Dosimetry and NTCP. Strahlenther Onkol. 2016;192(8):516-25. https://doi.org/10.1007/s00066-016-0980-1

PMid:27295511

10. Spiotto M, Weichselbaum R. Comparison of 3D confromal radiotherapy and intensity modulated radiotherapy with or without simultaneous integrated boost during concurrent chemoradiation for locally advanced head and neck cancers. PLoS One. 2014;9(4):e94456. https://doi.org/10.1371/journal. pone.0094456

PMid:24714187

11. Studer G, Huguenin PU, Davis JB, Kunz G, Lütolf UM, Glanzmann C. IMRT using simultaneously integrated boost (SIB) in head and neck cancer patients. Radiat Oncol. 2006;1(1):7. https://doi.org/10.1186/1748-717x-1-7 PMid: 16722599

12. SchwartzM, Vuong T, Ballivy O, ParkerW, Patrocinio H.Accelerated radiotherapy with simultaneous integrated boost fractionation and intensity-modulated radiotherapy for advanced head and neck cancer. Otolaryngol Head Neck Surg. 2007;136(4):549-55. https://doi.org/10.1016/j.otohns.2006.10.044

PMid: 17418249

13. Amin MB, Edge S, Greene FL, Byrd DR, Brookland RK, Washington MK, et al. AJCC Cancer Staging Manual. $8^{\text {th }}$ ed. New York: Springer-Verlag; 2017.

14. Radiation Therapy Oncology Group RTOG 0022 Phase I/II Study of Conformal and Intensity Modulatet Irradiation for Oropharyngeal Cancer; 2019. Available from: https://www.rtog.org/ClinicalTrials/ProtocolTable/StudyDetails. aspx?study $=0022$. [Last accessed on 2019 Jun 30].

15. Krstevska V, Smickoska S. Radioterapija na Kanceri na Glavata i Vratot. Skopje: Medicinski Fakultet; 2015. p. 54-61.

16. Cox J, Stetz J, Pajak T. Toxicity criteria of the radiation therapy oncology group (RTOG) and the European organization for research and treatment of cancer (EORTC). Int J Radiat Oncol Biol Phys. 1995;31(5):1341-6. https://doi. org/10.1016/0360-3016(95)00060-c

PMid:7713792 